Available online on 15.02 .2020 at http://jddtonline.info
Open Access to Pharmaceutical and Medical Research
unrestricted non-commercial use, provided the original work is properly cited

Open? Access

Review Article

\title{
Polymeric micelle as a nanocarrier for delivery of therapeutic agents: A comprehensive review
}

\author{
Roshani D. Agrawal*, Amol A. Tatode, Nilesh R. Rarokar, Milind J. Umekar \\ Department of Pharmaceutics, Smt. Kishoritai Bhoyar College of Pharmacy, Kamptee, Nagpur (M.S.) India
}

\begin{abstract}
For selective and effective drug delivery of therapeutic agent nanocarriers are the most effective agents. Micelles are an aggregate of surfactant molecules that dispersed in a liquid colloid. Micelles have a variety of shapes such as spheres, rods, vesicles, tubules, and lamellae. The shape and size of a micelle are a function of the molecular geometry of its surfactant molecules and solution conditions such as surfactant concentration, temperature, $\mathrm{pH}$, and ionic strength. Poly Ethylene Glycol (PEG) is the most commonly used hydrophilic segment of micelles for drug delivery. Besides PEG, other polymers including poly (N-vinyl pyrrolidone) (PVP) and poly (N-isopropyl acrylamide) (pNIPAM) have also been used as hydrophilic portion of micelles. In this review we all discus about the polymeric micelles (PMs) as a nanocarriers for delivery of therapeutic agents.
\end{abstract}

Keywords: Polymeric Micelles, Colloids, Nanocarriers, Drug Delivery, Poly Ethylene Glycol(PEG)

Article Info: Received 11 Nov 2019; Review Completed 04 Jan 2020; Accepted 10 Jan 2020; Available online 15 Feb 2020

Cite this article as:

Agrawal RD, Tatode AA, Rarokar NR, Umekar MJ, Polymeric micelle as a nanocarrier for delivery of therapeutic agents: A comprehensive review, Journal of Drug Delivery and Therapeutics. 2020; 10(1-s):191-195

http://dx.doi.org/10.22270/jddt.v10i1-s.3850

*Address for Correspondence:

Roshani D. Agrawal, Department of Pharmaceutics, Smt. Kishoritai Bhoyar College of Pharmacy, Kamptee, Nagpur (M.S.) India

\section{Introduction}

A micelle is a colloid formed by a surfactant in equilibrium with the molecules or with the ions that contribute at micelle formation. In the past decades, nanocarriers have emerged as an attractive research field in cancer therapy, including liposomes, micelles and nanoparticles made of various materials. Polymeric micelles (PMs) are extensively studied carriers for the delivery of poorly water-soluble drugs [1]

Based on the type of intermolecular forces driving the micelle formation, block copolymer micelles can be divided into several categories including hydrophobically assembled amphiphilic micelles, polyion-complex micelles, and micelles stemming from metal complexation [2]. The hydrophobically assembled micelles usually consist of amphiphilic macromolecules that have distinct hydrophobic and hydrophilic domains, and the commonly used block segments of copolymers have been summarized [3]. Upon exposure to aqueous medium, the amphiphilic molecules are spontaneously self-assembled into supramolecular core/shell structures and water-insoluble drugs can be loaded into the hydrophobic cores $[4,5]$.

Micelles have demonstrated a variety of shapes such as spheres, rods, vesicles, tubules, and lamellae depending on the relative length of hydrophobic/hydrophilic blocks as well as solvent environment [6-8]. Morphology of micelles has significant impact on the pharmacokinetic properties of micelles. For example, worm-like micelles have shown ten times longer circulation time compared with the spherical counterpart made of similar material [9]. The most commonly used hydrophilic segment of micelles for drug delivery is poly (ethylene glycol) (PEG), with a molecular weight of 2-15 kDa. PEG is highly water-soluble, non-toxic and neutrally charged. PEG forms a hydrophilic corona on the surface of micelles which minimizes the nonspecific interaction with blood components and prolongs the circulation time. Besides PEG, other polymers including poly(N-vinyl pyrolidone) (PVP) [10] and poly(N-isopropyl acrylamide) (pNIPAM) [11] have also been used as hydrophilic portion of micelles. 


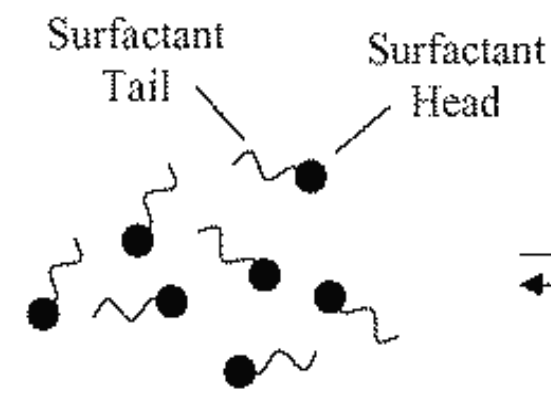

Surfactant Monomers

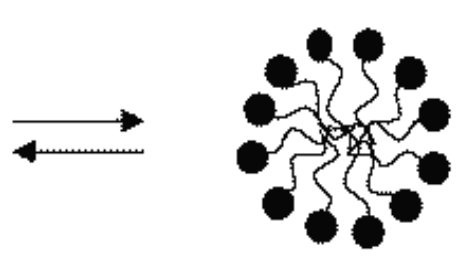

Micelle

Figure 1: Schemetic diagram of micelles formation

\section{Formation of Polymeric micelles}

PMs are self-assembled core-shell nanostructures formed in an aqueous solution consisting of amphiphilic block copolymers [12-14]. Formation of micelles in aqueous solution occur when the concentration of the block copolymer increases above a certain concentration named the critical aggregation concentration (CAC) or critical micelle concentration (CMC). At the CAC or CMC, hydrophobic segments of block copolymers start to associate to minimize the contact with water molecules, leading to the formation of a vesicular or core-shell micellar structure.
Theoretically, the formation of micelles is driven by decrease of free energy. The removal of hydrophobic fragments from the aqueous environment and the reestablishing of hydrogen bond network in water decrease free energy of the system and finally form the micelles. The typical methods used for encapsulation of poorly water-soluble drugs are dialysis method, oil-in-water emulsion solvent evaporation method, and solid dispersion method $[\mathbf{1 5}, \mathbf{1 6}]$. Other methods used are direct dissolution $[\mathbf{1 7}, \mathbf{1 8}]$, complexation [19], chemical conjugation [20], and various solvent evaporation procedures [21].
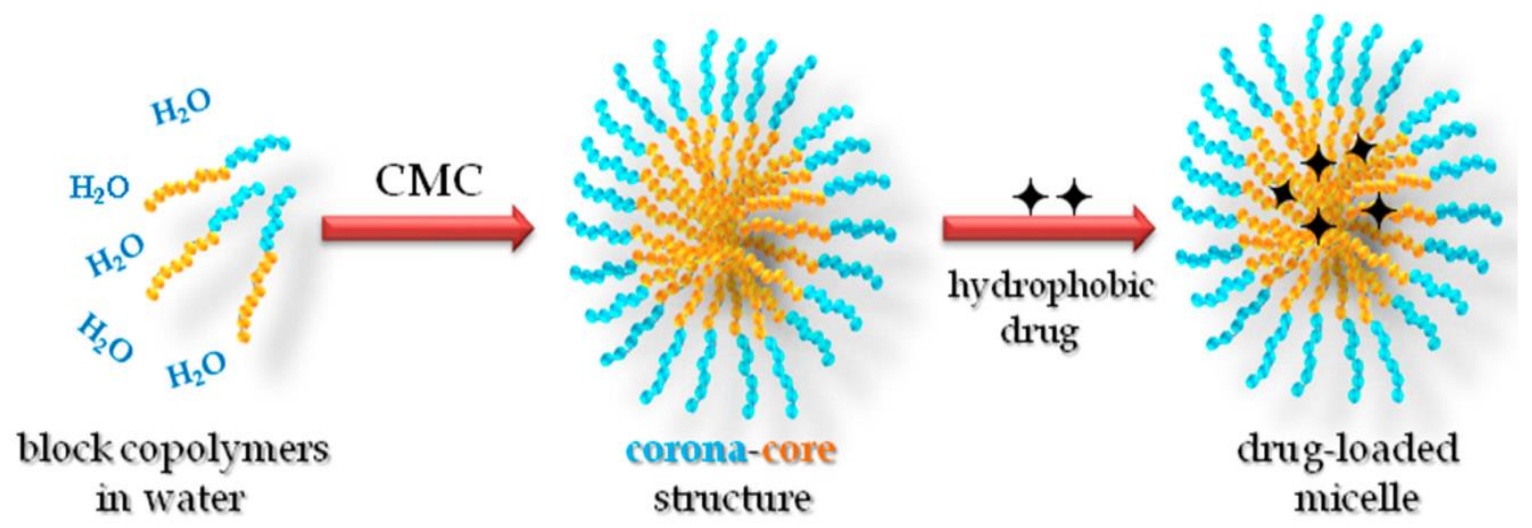

Figure 2: formation of drug loaded micelles

\section{3. pH sensitive PMs}

The potential disadvantage of normal PMs can be solved by application of additional stimuli that cause micelle destabilization in a specially controlled manner thus increasing the selectivity and efficiency of drug delivery to target sites. External factors such as heat [22, 23], light [24], and sound (ultrasound) $[\mathbf{2 5 , 2 6}]$ have already been studied by many researchers. However, these external stimuli may only activate the carriers that are situated closely underneath the skin but not those deeply distributed in the body. The intracellular signals also play an important role in regulating drug release which causes a great deal of interests, and here we focus our attention on $\mathrm{pH}$-responsive systems.

\section{Mucoadhesive PMs}

Nanocarriers for oral administration should adhere to mucus and cross the mucus layer. Drugs delivered to mucosal surfaces are usually efficiently removed by mucus clearance mechanisms [27]. The luminal surface of mucosal tissues is protected by a highly viscoelastic layer [28], and the protective coatings rapidly remove foreign particles from the GI tract which probably lead to low bioavailability. Unlike the relatively high requirements of intravenous infusions, oral formulations could include high-molecular weight polymers as long as these components are metabolizable and cannot find their way into the systemic circulation. Hence, it may be an effective means of increasing uptake of drugs with mucoadhesive PMs $[29,30]$, and there have been considerable interests in the concept of mucoadhesive PMs.

\section{Micelles with built-in drug-interactive domain as improved delivery systems}

The drug-loading capacity of polymeric micelles is critically dependent on the compatibility between the drug and the micelle core [31]. A series of studies have demonstrated that 
the drug-loading capacity of micelles can be greatly enhanced by optimizing chemical structures of the inner core segment for stronger drug/carrier interaction. A typical example of the strategy for enhanced compatibility between drug and block copolymer is the development of hydrotropic polymers. Hydrotropy refers to a phenomenon that the aqueous solubility of a poorly soluble compound is significantly enhanced by the presence of large amounts of a second solute, named hydrotrope [32]. The hydrotropes aggregate only above a certain concentration, which is known as the minimal hydrotrope concentration (MHC) [33]. Various studies have been carried out to elucidate the process of hydrotropic solubilization. Although the exact mechanism is not fully clarified, it may involve multiple noncovalent interactions including hydrophobic interaction, hydrogen bonding [30] as well as parallel stacking effect $[34,35]$.

\section{PEG-drug conjugates as dual-function carriers for cancer targeted delivery}

PEG-Vitamin E Conjugates as Dual-Function Carriers for Cancer-Targeted Delivery D- $\alpha$-tocopheryl polyethylene glycol (PEG) 1,000 succinate (TPGS) is a PEG-derivatized natural vitamin $E$ which has been approved by FDA as a safe pharmaceutical adjuvant for drug formulation. In recent years, the application of TPGS in drug formulations has been extensively studied, such as emulsifier in poly (lactic-coglycolic acid) (PLGA) nanoparticles, solubilizer and permeation enhancer [36], TPGS based liposomes [37], copolymers [38], and nanocrystal [39]. By inhibiting the function of P-glycoprotein (P-gp), TPGS also helps to overcome the multidrug resistance $[40]$ and enhance the oral bioavailability of anticancer drugs [41]. In addition, TPGS-doxorubicin conjugate was develop ed as a prodrug for enhanced therapeutic effect [42].
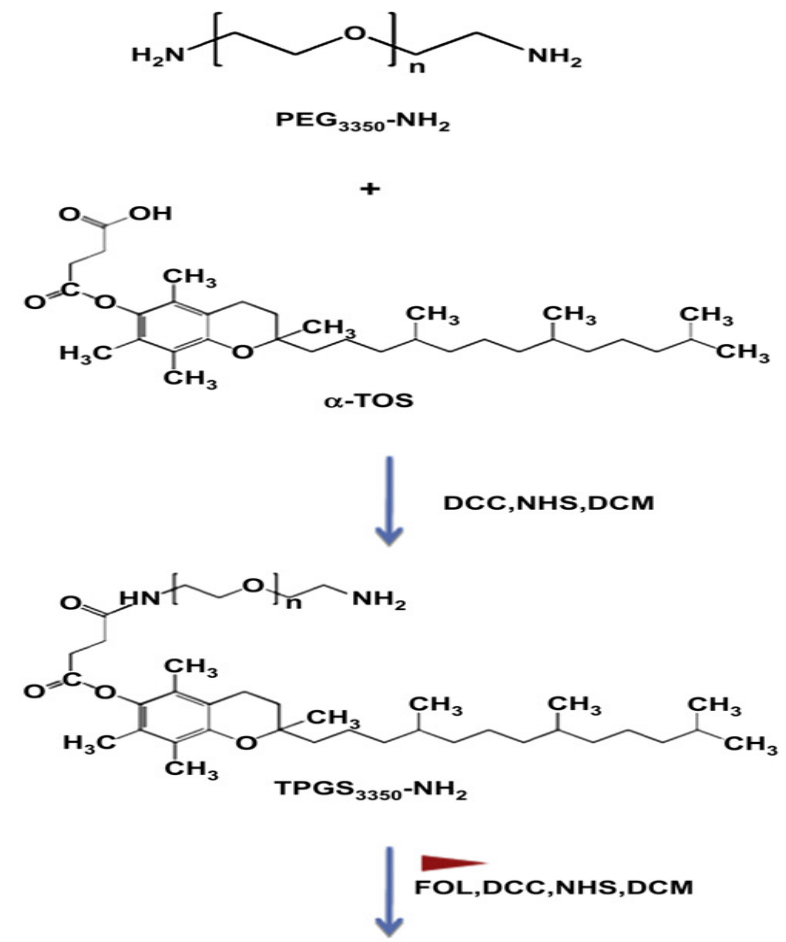

TPGS $_{2 k}$
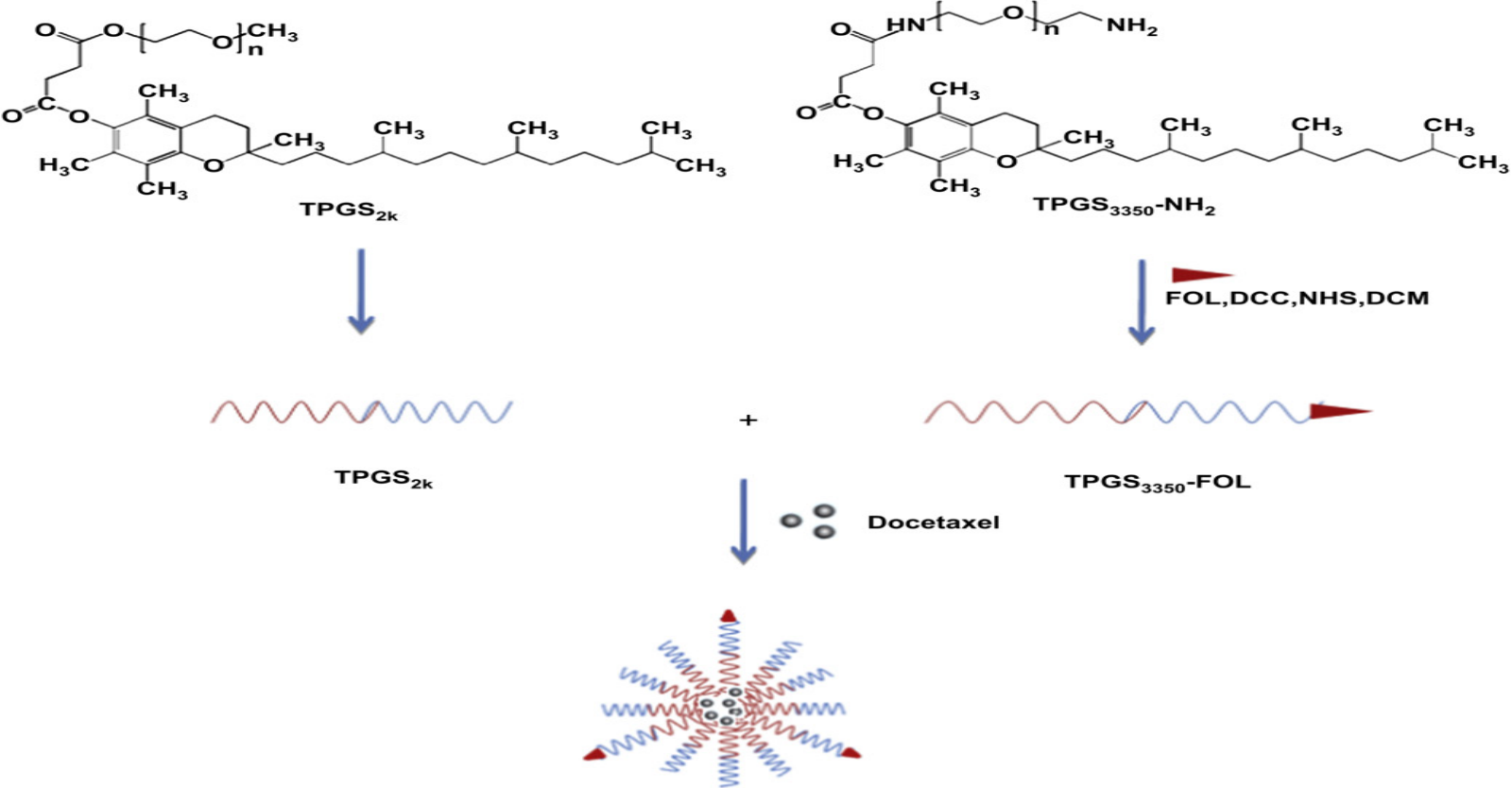

Figure 3: Preparation scheme for folic acid conjugated TPGS2k micelles loaded with Docetaxel as a model drug.

\section{PEG-derivatized Embelin as a nanocarrier}

Bearing a long lipophilic chain, embelin is extremely hydrophobic and water-insoluble. In an attempt to explore the PEG modification as an approach to increase its water solubility, we have found that PEG-derivatized embelin forms micelles in aqueous solution [43]. This is not a surprise considering the structural similarity between embelin and vitamin E. Interestingly, the antitumor activity of embelin was well retained after coupling with PEG chain [43]. In addition, the PEG-embelin micelles are highly efficient in solubilizing various types of anticancer agent such as paclitaxel $[\mathbf{4 3}, \mathbf{4 4}]$. Furthermore, PEG-embelin, at nanomolar range, showed synergistic effect with paclitaxel in several cancer cell lines tested [45] 


\section{Conclusion}

Overall study revealed that the polymeric micelles have potential to be act as a targeted nanocarrier for delivery of various therapeutic agents. Hence polymeric micelles can be used for the drug delivery application.

\section{References}

1. Yifei Zhang, Yixian Huang, and Song Li .,Polymeric Micelles: Nanocarriers for Cancer-Targeted Drug Delivery

2. Gaucher G, Dufresne MH, Sant VP, Kang N, Maysinger D, Leroux JC. Block copolymer micelles: preparation, characterization and application in drug delivery. J Control Release. 2005; 109(1-3):169-88.

3. Sutton D, Nasongkla N, Blanco E, Gao J. Functionalized micellar systems for cancer targeted drug delivery. Pharm Res. 2007; 24(6):1029-46.

4. Rarokar NR, Khedekar PB, Formulation and evaluation of docetaxel trihydrate loaded self-assembled nanocarriers for treatment of HER 2 positive breast cancer. Journal of drug delivery and Therapeutics. 2017; 7(6):1-6

5. Rarokar N. R., Khedekar P. B., Bharne A., Umekar M., Development of self-assembled nanocarriers to enhance antitumor efficacy of docetaxel trihydrate in MDA-MB-231 cell line, Int. J. Biol. Macromol. 125 (2019) 1056-1068. DOI:doi.org/10.1016/j.ijbiomac.2018.12.130

6. Choucair A, Eisenberg A. Control of amphiphilic block copolymer morphologies using solution conditions. Eur Phys J E Soft Matter. 2003; 10(1):37-44.

7. Yu Y, Zhang L, Eisenberg A. Morphogenic effect of solvent on crew-cut aggregates of amphiphilic diblock copolymers. Macromolecules. 1998; 31(4):1144-54.

8. Shen H, Zhang L, Eisenberg A. Multiple pH-induced morphological changes in aggregates of polystyrene-blockpoly(4-vinylpyridine) in DMF/H2O mixtures. J Am Chem Soc. 1999; 121(12):2728-40.

9. Geng Y, Dalhaimer P, Cai S, Tsai R, Tewari M, Minko T, et al. Shape effects of filaments versus spherical particles in flow and drug delivery. Nat Nanotechnol. 2007; 2(4):249-55.

10. Benahmed A, Ranger M, Leroux JC. Novel polymeric micelles based on the amphiphilic diblock copolymer poly(N-vinyl-2pyrrolidone)-block-poly(D, L-lactide). Pharm Res. 2001; 18(3):3238.

11. Chung JE, Yokoyama M, Aoyagi T, Sakurai Y, Okano T. Effect of molecular architecture of hydrophobically modified poly(Nisopropylacrylamide) on the formation of thermoresponsive core-shell micellar drug carriers. J Control Release. 1998; 53(1- 3):119-30.

12. Riess G., "Micellization of block copolymers," Progress in Polymer Science, vol. 28, no. 7, pp. 1107-1170, 2003. View at Publisher - View at Google Scholar • View at Scopus

13. Jones M.-C. and J.-C. Leroux, "Polymeric micelles-a new generation of colloidal drug carriers," European Journal of Pharmaceutics and Biopharmaceutics, vol. 48, no. 2, pp. 101111, 1999. View at Publisher · View at Google Scholar · View at Scopus

14. Rarokar N.R., Saoji S.D., Khedekar P.B., Investigation of effectiveness of some extensively used polymers on thermoreversible properties of Pluronic $₫$ tri-block copolymers, J. Drug Delivery Sci. Technol. 44 (2018) 220-230. DOI:doi.org/10.1016/j.jddst.2017.12.002

15. Van Butsele K., Sibret P., Fustin C. A. et al., "Synthesis and pHdependent micellization of diblock copolymer mixtures," Journal of Colloid and Interface Science, vol. 329, no. 2, pp. 235-243, 2009. View at Publisher - View at Google Scholar - View at Scopus

16. Parajapati SK, Maurya SD, Das MK, Tilak VK, Verma KK, Dhakar RC, Potential application of dendrimers in drug delivery: A concise review and update, Journal of Drug Delivery and Therapeutics 2016; 6(2):71-88

17. Alakhov V. Y., Moskaleva E. Y., Batrakova E. V., and A. V. Kabanov, "Hypersensitization of multidrug resistant human ovarian carcinoma cells by pluronic P85 block copolymer," Bioconjugate Chemistry, vol. 7, no. 2, pp. 209216, 1996. View at Google Scholar · View at Scopus .

18. Rarokar N.R., S.D. Saoji, N.A. Raut, J.B. Taksande, P.B. Khedekar, V.S. Dave, Nanostructured cubosomes in a thermoresponsive depot system: an alternative approach for the controlled delivery of docetaxel, AAPS PharmSciTech 17 (2015) 436-445. DOI:10.1208/s12249-015-0369-y

19. Nishiyama N., Kataoka K., "Preparation and characterization of size-controlled polymeric micelle containing cisdichlorodiammineplatinum(II) in the core," Journal of Controlled Release, vol. 74, no. 1-3, pp. 83-94, 2001. View at Publisher • View at Google Scholar · View at Scopus

20. Y. Li and G. S. Kwon, "Methotrexate esters of poly(ethylene oxide)-block-poly(2-hydroxyethyl-L- aspartamide). Part I: effects of the level of methotrexate conjugation on the stability of micelles and on drug release," Pharmaceutical Research, vol. 17, no. 5, pp. 607-611, 2000. View at Publisher · View at Google Scholar · View at Scopus .

21. Lavasanifar A., Samuel J., and G. S. Kwon, "Micelles selfassembled from poly(ethylene oxide)-block-poly(N-hexyl stearate L-aspartamide) by a solvent evaporation method: effect on the solubilization and haemolytic activity of amphotericin B," Journal of Controlled Release, vol. 77, no. 12, pp. 155-160, 2001. View at Publisher - View at Google Scholar $\cdot$ View at Scopus

22. Tan R., She Z., M. Wang, Z. Fang, Y. Liu, and Q. Feng, "Thermosensitive alginate-based injectable hydrogel for tissue engineering," Carbohydrate Polymers, vol. 87, no. 2, pp. 15151521, 2012. View at Publisher · View at Google Scholar · View at Scopus .

23. Liu G., X. Li, S. Xiong et al., "Fluorine-containing thermosensitive core/shell microgel particles: preparation, characterization, and their applications in controlled drug release," Journal of Fluorine Chemistry, vol. 135, pp. 75-82, 2012. View at Publisher - View at Google Scholar - View at Scopus

24. Chen C. J., Q. Jin, G. Y. Liu, D. D. Li, J. L. Wang, and J. Ji, "Reversibly light-responsive micelles constructed via a simple modification of hyperbranched polymers with chromophores," Polymer, vol. 53, no. 17, pp. 3695-3703, 2012. View at Publisher - View at Google Scholar

25. Husseini G. A., Velluto D., L. Kherbeck, W. G. Pitt, J. A. Hubbell, and D. A. Christensen, "Investigating the acoustic release of doxorubicin from targeted micelles," Colloids and Surfaces B, vol. 101, pp. 153-155, 2013. View at Publisher. View at Google Scholar

26. Yin T., Wang P., Li J. et al., "Ultrasound-sensitive siRNA-loaded nanobubbles formed by hetero-assembly of polymeric micelles and liposomes and their therapeutic effect in gliomas," Biomaterials, vol. 34, no. 18, pp. 4532-4543, 2013. View at Publisher • View at Google Scholar .

27. Tang B. C., Dawson M., Lai S. K. et al., "Biodegradable polymer nanoparticles that rapidly penetrate the human mucus barrier," Proceedings of the National Academy of Sciences of the United States of America, vol. 106, no. 46, pp. 1926819273, 2009. View at Publisher-View at Google Scholar $\cdot$ View at Scopus .

28. Cone R. A., "Barrier properties of mucus," Advanced Drug Delivery Reviews, vol. 61, no. 2, pp. 75-85, 2009. View at Publisher · View at Google Scholar • View at Scopus

29. Rahmat D., Muller C., Barthelmes J., Shahnaz G., R. Martien, and Schnurch A. B., "Thiolated hydroxyethyl cellulose: design and in vitro evaluation of mucoadhesive and permeation enhancing nanoparticles," European Journal of Pharmaceutics and Biopharmaceutics, vol. 83, no. 2, pp. 149-155, 2013. View at Publisher - View at Google Scholar

30. Srivalli K. M. R., Lakshmi P. K., and Balasubramaniam J., "Design of a novel bilayered gastric mucoadhesive system for localized and unidirectional release of lamotrigine," Saudi Pharmaceutical Journal, vol. 21, no. 1, pp. 45-52, 2013. View at Publisher - View at Google Scholar - View at Scopus

31. Latere Dwan'Isa JP, Rouxhet L, Preat V, Brewster ME, Arien A. Prediction of drug solubility in amphiphilic di-block copolymer micelles: the role of polymer-drug compatibility. Pharmazie. 2007;62(7):499-504.

32. Coffman R, Kildsig D. Hydrotropic solubilization-mechanistic studies. Pharm Res. 1996; 13(10):1460-3.

33. Bauduin P, Renoncourt A, Kopf A, Touraud D, Kunz W. Unified concept of solubilization in water by hydrotropes and cosolvents. Langmuir. 2005; 21(15):6769-75. 
34. Kim JY, Kim S, Papp M, Park K, Pinal R. Hydrotropic solubilization of poorly water-soluble drugs. J Pharm Sci. 2010; 99(9):3953-65.

35. Cui Y. Parallel stacking of caffeine with riboflavin in aqueous solutions: the potential mechanism for hydrotropic solubilization of riboflavin. Int J Pharm. 2010; 397(1-2):3643.

36. Ooya T, Lee S, Huh K, Park K. Hydrotropic nanocarriers for poorly soluble drugs. In: Mozafari MR, editor. Nanocarrier technologies. Netherlands: Springer; 2006. p. 51-73.

37. Yu L, Bridgers A, Polli J, Vickers A, Long S, Roy A, et al. Vitamin E-TPGS increases absorption flux of an HIV protease inhibitor by enhancing its solubility and permeability. Pharm Res. 1999; 16(12):1812-7.

38. Muthu MS, Kulkarni SA, Xiong J, Feng SS. Vitamin E TPGS coated liposomes enhanced cellular uptake and cytotoxicity of docetaxel in brain cancer cells. Int J Pharm. 2011; 421(2):332-40.

39. Zhang Z, Feng SS. Nanoparticles of poly(lactide)/vitamin E TPGS copolymer for cancer chemotherapy: synthesis, formulation, characterization and in vitro drug release. Biomaterials. 2006; 27(2):262-70.
40. Liu Y, Huang L, Liu F. Paclitaxel nanocrystals for overcoming multidrug resistance in cancer. Mol Pharm. 2010;7(3):863-9.

41. Cheng $X$, Developing organic and inorganic nanomedicine for cancer therapy, Journal of Drug Delivery and Therapeutics. 2017; 7(2):1-4

42. Varma MV, Panchagnula R. Enhanced oral paclitaxel absorption with vitamin E-TPGS: effect on solubility and permeability in vitro, in situ and in vivo. Eur J Pharm Sci. 2005; 25(4-5):44553.

43. Cao N, Feng SS. Doxorubicin conjugated to D-alpha-tocopheryl polyethylene glycol 1000 succinate (TPGS): conjugation chemistry, characterization, in vitro and in vivo evaluation. Biomaterials. 2008; 29(28):3856-65.

44. Huang Y, Lu J, Gao X, Li J, Zhao W, Sun M, et al. PEGderivatized embelin as a dual functional carrier for the delivery of paclitaxel. Bioconjug Chem. 2012; 23(7):1443-51.

45. Lu J, Huang Y, Zhao W, Marquez RT, Meng X, Li J, et al. PEGderivatized embelin as a nanomicellar carrier for delivery of paclitaxel to breast and prostate cancers. Biomaterials. 2013; 34(5):1591-600. 